\title{
Transition from Vertical to Horizontal Industrial Policy in Ukraine: Effects on Industrial Sector Growth
}

\author{
Liudmyla Deineko ${ }^{l}$, Olena Tsyplitska ${ }^{{ }^{*}}$, Nadiia Hrebeniuk ${ }^{2}$, and Oleksandr Deineko ${ }^{3}$ \\ ${ }^{1}$ State Organization "Institute for Economics and Forecasting of NAS of Ukraine”, Department of Industrial Policy, 01011, Kyiv, \\ Ukraine \\ ${ }^{2}$ King Danylo University, Department of Finance and Accounting, 76018, Ivano-Frankivsk, Ukraine \\ ${ }^{3}$ Ukrainian-American Concordia University, Department of International Economic Relations, Business, and Management, 01054, Kyiv, \\ Ukraine
}

\begin{abstract}
This paper explores the determinants of industry's value added growth related to transition of Ukrainian industrial policy from vertical to horizontal type in 2015. The method used is econometric modelling through building multiple linear regression, where the real rates of value added growth from year to year represent the dependent variable. As explanatory variables the real rates of capital investments, structural changes, institutional indicators of regulatory quality and index of economic freedom as well as dummy-variables denoting the periods associated with industrial policy transit were introduced into the model. The main finding of the study is the revealed negative effect of horizontal industrial policy on industrial sector productivity. Other results showed the significant contribution of capital investments growth rates and government support's share in the State budget expenditures. The included institutional determinants as well as structural changes indicator didn't play any significant role in providing of industry's value added growth. The results of modelling were used in recommendations for matrix (combination of vertical and horizontal instruments) policy implementation in Ukraine.
\end{abstract}

\section{Introduction}

Industrial policy stands as one of the most important tools in the field of creating a structurally balanced, competitive economy, within which the latest technological and institutional trends are implemented. Adjustment of conceptual approaches and targets for its development and implementation is called for, in the light of the new challenges of the Industry 4.0, "green" modernization and inclusive development in transformational economies, integration processes in Central and Eastern Europe and the growing numbers of participants in international trade agreements. If the goal of industrial policy in the XIX-XX centuries was to create a strong industrial sector, at the present stage it is adjusted to environmental, social, and institutional aspects as the prerequisites for the implementation of any technological solutions.

The signing of the Association Agreement between Ukraine and the EU was also the basis for a revision of the dominant - vertical (sectoral) - approach to the selection of industrial policy instruments. EU member states and other developed countries ensure a balance between sectoral and horizontal means of supporting industrial development, forming a so-called matrix model of industrial policy.

In Ukraine as a result of the armed conflict in the Donbas region depleting the economic potential of both the temporarily occupied territories and the country as a whole, and the introduction of the European integration vector of development, the share of sectoral support in the state budget has been reduced. Such a "transition" from the dirigiste model of industrial development management, which, to some extent, led to the oligarchizing of the Ukrainian economy, to the liberal model, created an additional "shock" in the domestic market which has led to a significant decline in conditions of COVID-19 pandemic. In mining and quarrying industry, the volumes of production fell by 4.2 (I quarter), by 8.7 (II quarter), and by $0.8 \%$ (III quarter) in 2020; in manufacturing the indicator fell respectively by $4.3,14.7$, and $5.6 \%$.

Domestic industry, left alone with outdated fixed assets, products that do not meet international standards (in particular - European), import dependence, loss of the Russian market, critical lack of investment and credit resources etc., responded with a significant drop in production, reduced numbers of enterprises and outflow of investment and labor, negatively affecting the growth rates of the economy.

Hence, the assessment of the possible impact of state support for industrial development in Ukraine is especially relevant, to offset the negative effects of a market economy, as well as the impact of other factors economic, institutional, and political, which will adjust the course of industrial policy to accelerate economic growth of the industrial sector. This constitutes the goal of this research.

\subsection{Literature review}

\footnotetext{
* Corresponding author: $\underline{\text { o.liakhovetz@gmail.com }}$
} 
The state industrial policy is developed for negating negative and exploiting positive externalities of a market in the conditions of certain restrictions, namely:

1) lack of information, which is manifested in the inability to accurately identify industries, sectors or activities that are significantly affected by externalities, and therefore does not allow to fully compensate for their negative impact;

2) political commitment, through which the governing bodies cannot resist lobbying and rent orientation in order to prevent the transformation of industrial policy into tools for rent transfer to related insiders.

These factors determine the ineffectiveness of institutional mechanisms for modernization of the industrial sector, including direct state support. Mathematically, this will be reflected in the feedback between sectoral aid and the growth rate of productivity of the industrial sector [1], which can be represented as:

$$
g_{i}=\gamma s_{i}+\varepsilon_{i},
$$

where $g_{i}$ is a variable that indicates the efficiency of the sector, for example, productivity; $s_{i}-$ government intervention as a sectoral policy; $\gamma$ - parameter that represent the success of industrial policy; $\varepsilon$ - model error.

The success of an industrial policy will be manifested in the sign of the coefficient $\gamma$ : if it is greater than zero, the policy is effective, if less, then vice versa. The theoretical generalization developed by D. Rodrik [1] demonstrates that, in fact, the policy will always be ineffective. Considering a simple model (2):

$$
g_{i}=\left(1-\theta_{i}\right) \cdot A,
$$

where $\mathrm{A}$ - productivity growth rate; $\theta_{i}$ - the extent of market failure, D. Rodrik mathematically confirms that the impact of government support will always have a negative sign of the relevant parameter, so the relationship between government aid and productivity growth is negative in the model, which assumes that the government pursues only public interests - maximizing the growth of productivity of industries. Even if a state applies the optimal level of subsidies and other assistance, it cannot fully eliminate all market failures, so $\gamma<0$. This becomes the basis for legislative regulation of the extent of government intervention. Based on this, regardless of whose interests a state pursues, the policy of intervention will bring a negative result.

Determination of the effectiveness of state mechanisms in support of the industrial sector is reflected in a set of econometric models by R. Beason, D. E. Weinstein [2]; C. Criscuolo, R. Martin, H.G. Overman, J. Van Reenen [3]; A.O. Krueger, B. Tuncer [4]; R.Z. Lawrence, D.E. Weinstein [5]; J.-W. Lee [6]; R. Stöllinger et al. [7]; J. Wang [8]; H.-Y. Joo, H. Suh [9]; J. Chen, L. Xie [10]; Y. Higuchi, G. Shimada [11]. Despite the existing discourse in the economic scientific community about the essence of industrial policy, its tools and their effectiveness, empirical research using statistical and economic modeling is quite small. However, some results were obtained from the analysis of developed countries - EU member states, Japan,
Turkey, and the Republic of Korea.

R.Z. Lawrence, D.E. Weinstein [5] tested a popular hypothesis that state protectionism in Japan has increased the competitiveness of manufacturing companies at the global level by building an econometric model of the impact of industrial policy on the overall productivity of the industrial sector. The model included variables such as the level of technological backwardness, cumulative growth rates in industries since 1960 as effects of "learning-by-doing", R\&D expenditures, the share of imports in domestic consumption, the share of exports in total intake, the level of tariff protection and individual industrial policy measures. The simulation results refuted the hypothesis of the usefulness of state protectionism. On the contrary, the stimulating role of imports to increase the competitiveness of domestic producers was proved, especially in the period 1964-1973, which led the authors to conclude the beneficial nature of the liberal model for the Japanese economy.

A.O. Krueger, B. Tuncer [4] assessed the dependence of the growth rate of industrial sector output (emerging industries) on the growth rate of state protectionism in Turkey, in particular, in the framework of tariff policy. They've built an econometric model of the dependence of these variables, considering the cost function of the industrial sector. The main assumption was that effective government support should have resulted in lower production costs per unit of output. As a result, it turned out that in the protected industries there was no increase in productivity per unit of output to give the justification for such state protection. However, researchers suggested that the reason may lie in the inappropriate incentives structure.

Based on the correlation analysis, a negative relationship between the types of government support and the growth rate of production in Japan was found by R. Beason, D. E. Weinstein [2] in different periods from 1955 to 1990 . Researchers also built a linear function of industrial policy's influence on the productivity of the industrial sector (3):

$$
\Psi_{t}=f(L(D T A X) L(D J D B), L(D S U B), L(D T A R),
$$

$$
L(T A R), L(N T B)) \text {, }
$$

where $L(\cdot)$ is the lag field of policy of variables; DTAXtax relief variable; $D J D B$ - Japan Development Bank loans variable; $D S U B$ - subsidies variable; DTAR - the difference between the sectoral tariff rate and the average tariff rate; TAR - effective rate of protection in the sector; NTB - the percentage of subsectors within a given sector covered by quotas.

As a result, it was concluded that state support in Japan was not directed to high-tech sectors, seemingly due to the erroneousness of government decisions in the choice of priority areas of development, and such support did not lead to productivity growth in the studied areas.

J.-W. Lee [6] studied the impact of state industrial policy on productivity growth in the Republic of Korea's industrial sector. The empirical results of econometric modeling, which evaluated the effectiveness of measures 
such as non-tariff barriers, customs tariffs, tax incentives and credit incentives, disprove the popular notion of the success of government intervention in the Korean economy. Empirical results have failed to confirm any positive effect of government interventions on labor productivity. Some positive effects were achieved only through tax privileges. As a result, the author believes that the Republic of Korea's success would be more significant without government intervention.

Other scholars, J. Chen \& L. Xie [10] considering the predominantly sectoral approach to industrial policy in China tested the correlation between the policy measures and industrial performance from 2003 to 2015 on several regression models (including explanatory variables of capital, population, the level of informatization, transport level, human capital level, opening-up level, and the extent of government intervention). They concluded that sectoral industrial policy was the main locomotive of development in industrial sector in spite of extension of horizontal (functional) instruments in recent years.

In the context of the EU member states, researchers R. Stöllinger et al. [7] determined the impact of different types of state aid provided to EU countries on exportoriented sectors of the processing industry, using threestage regression. Among the types of assistance were considered the following: state subsidies for environmental protection, aid for R\&D, regional development, assistance to strategic sectors (shipbuilding, steel, aviation, etc.) and other types of horizontal support. To make the results more valid, government efficiency indicators (to control the quality of institutions), the share of wages in value added (as an indirect indicator of competitiveness), and the weighted import tariff rate (as an indicator of trade protection) were added to the model. The simulation results revealed that the only significant type of state support could be the expenditures on the internationalization of production, which should occur along with the improvement of governance efficiency. Thus, for some countries with a very low level of public administration efficiency, such assistance may be counterproductive. However, there is a group of countries with a high share of exports, but with a low level of government efficiency, so, depending on the institutional conditions, different strategies can be applied to increase exports. Overall, both in terms of value added and in terms of growth, sectoral processing aid in the EU has not yielded any significant results.

More recent studies allow estimating the performance and configuration of government support for industrial sector by innovation-driving, employmentincreasing, and environmental-protecting measures.

The comparison between Singapore and Hong Kong industrial policies and forms of government intervention into innovative activities in the research of J. Wang [8] suggested that stronger state presence on the market leaded big companies to a significant progress in innovative development while some horizontal measures in Hong Kong became the base for some innovations emerging from small and medium business. However, in general innovative development in Hong Kong was slowing down. The author tested the hypotheses using the negative binomial regression for industries in Singapore and Hong Kong. The approach was based on the accounting of the quantity of patents issued by each country. The conclusion was to strengthen the government intervention to stimulate innovative industrial development.

The environmental issues of industrial exporting small \& medium companies in Korea and China were studied by H.-Y. Joo and H. Suh [9]. The scholars used the distinction of market, environmental and export performance between the companies as dependent variables to reveal the mediating effects of different countries in the relationship between government support and company performances. As the result, the assistance for introduction of eco-innovations has become the most significant outcome of the interventions.

Y. Higuchi and G. Shimada [11] discussed the controversy of interventionist policy on the examples of Asian and African states. The have widely analyzed the employment in industrial and other economic sectors over years. The model of decomposition of gross domestic product (GDP) per capita ensured the perspective of "training-infrastructure-finance" (TIF) strategy of government intervention in industrial production sphere in African countries in order to set up the high rates of industrial productivity growth. Thus the combination of horizontal (training and infrastructure development) and vertical (direct financing) measures would provide the comparative advantages over Asian countries in the labor-intensive industries.

A team of EU researchers led by C. Criscuolo [3] has found a positive contribution between the regional selective support in European countries and the job growth, considering that only some regions of the EU are eligible for such assistance. The greatest effect was observed for small enterprises, while for the large ones it was insignificant. The following econometric model (4) was evaluated:

$$
y_{r, t}=\lambda_{1} N G E_{r, t}+\eta_{r}+\tau_{r}+v_{r, t}
$$

where $N G E_{r, t}-$ Net Grant Equivalent, which is the key policy variable and is defined as the maximum investment subsidy available in ward area $r$ in year $t$ and ranges from 0 to 35 percent; $y_{r, t}$ - employment; $\eta_{r}$ - area fixes effect; $\tau_{t}$ - time dummies; $\mathrm{v}_{r, t}-$ error.

The modelling revealed that the program reduced unemployment and increased employment in the manufacturing industry, but no impact on productivity was found. This gives grounds to consider the model of effectiveness of state support for industrial modernization in Ukraine, which includes both direct expenditures on sectoral development and the expenditures on R\&D in relevant sectors, as well as the implementation of strategies for the development of the industrial sector.

\subsection{Data and methodology}


Since the growth of the industrial sector makes a direct contribution to the economic growth in general, it is necessary to assess whether the state budget expenditures for the restructuring of the industrial sector and its modernization are productive. The share of public expenditures to support the industrial sector in total state budget expenditures is presented in Fig. 1.

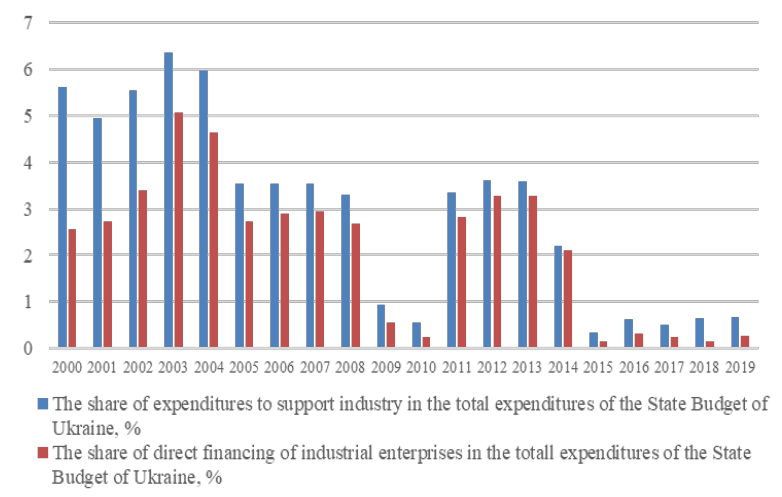

Fig. 1. The share of expenditures of the State budget of

Ukraine on support for the industrial sector in 2000-2019, \%

Modernization transformations and growth of gross value added in the industrial sector cannot be carried out without a corresponding inflow of capital investments. To stimulate economic growth in the sector, the dynamics of the growth of the latter must be positive. Empirical data for Ukraine in 2002-2018 indicates the connection between these two indicators (Fig. 2). The coefficient of correlation is equal to 0.77 , which confirms a strong relationship between the variables.

In addition, as an important component of the impact on the productivity of the industrial sector can be considered its natural and stimulated restructuring, which, as mentioned above, should go from low to high value added activities.

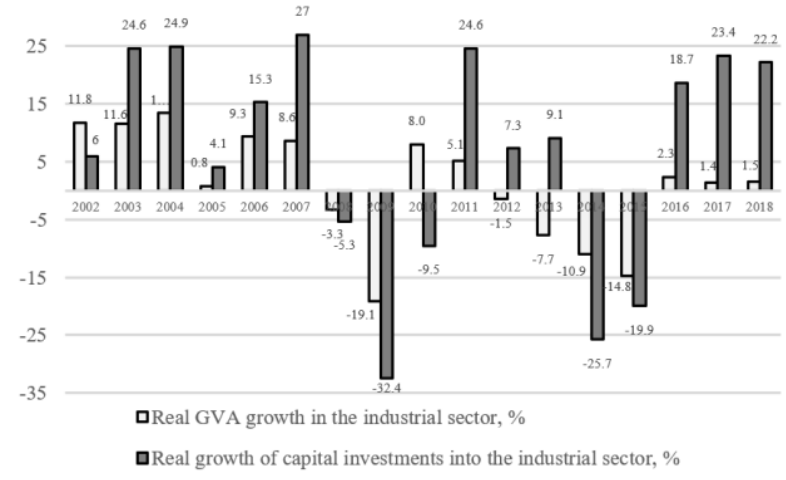

Fig. 2. Real growth in value added of industrial sector and capital investments, \%, 2002-2018

Taking into account the model of endogenous economic growth proposed by B. Buhm and L.F. Punzo [12], in which structural shifts are the key factor, the inclusion of this factor in the econometric model will reveal the extent of the impact of structural adjustment of the industrial sector on its growth rate. The measurement of structural changes was carried out by determining the quadratic coefficients of structural changes (up to the previous year) (Fig. 3), calculated according to the tables "Input-output" in basic prices for the period 2001-2018.

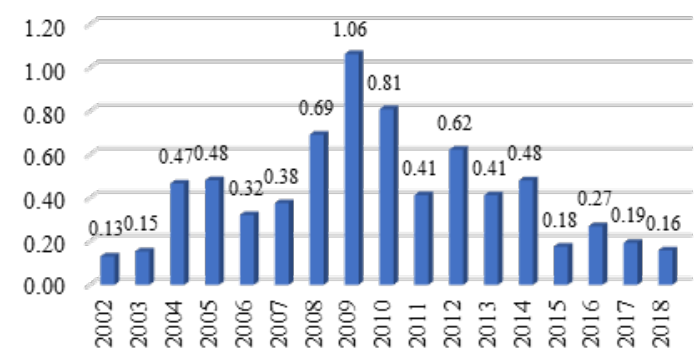

Fig. 3. Quadratic coefficient of structural changes in the industrial sector (chain), 2002-2018

The quadratic coefficient shows how many percentage points, on average, the industrial activities' shares deviate from each other. During the researched period. In order to ensure statistical homogeneity and comparability, the indicators of gross value added in different years were aggregated. Thus, in 2012-2018, the production of chemicals and chemical products, basic pharmaceutical products and pharmaceuticals and rubber and plastic products were combined into the chemical industry to meet the indicators of 2001-2011.

The dynamics of the quadratic coefficient of structural changes indicates a significant impact of the crisis of 2008-2009 on the change in the structure of industrial production. There was a reduction in the share of the extractive industry in GDP from $6.6 \%$ in 2008 to $5.1 \%$ in 2009 . The share of the food industry increased (from 4.9 to $6.5 \%$, respectively), which is a characteristic of economic stagnation, when the reduction of industrial production calls for less raw materials and investment goods, and more consumer goods part becomes more significant. In fact, the volumes of gross value added of metallurgy decreased by two times (from $5.3 \%$ to $2.5 \%$ ). Significant changes also took place in 2012, when the next phase of the decline in industrial production took place. If in 2011 the mining industry reached $7.8 \%$ of GDP, in 2012 its share decreased to $6.5 \%$, while metallurgical production increased from 1.6 to $2.3 \%$ of GDP. As for the processing industry, most of the activities producing consumer goods (food production, textile production, wood, and paper production), as well as mechanical engineering products, collectively reduced their shares in GDP. In 2016-2018, low growth rates of gross value added (GVA) in the industrial sector were accompanied by weak structural changes, as evidenced by the low values of the coefficients.

In total, for the studied period from 2002 to 2018, the coefficient of structural changes was 1.52 , which indicates a significant structural adjustment of industrial production for the studied period. The share of the extractive industry in GDP increased by $2 \%$, but, in addition to the production of furniture and other products, repair and installation of machinery and equipment, in virtually all branches of the processing industry there was a reduction in the share of GDP. Metallurgical production and production of metal products ( $4 \%$ of GDP), mechanical engineering ( $2 \%)$, food industry $(1.8 \%)$, chemical industry $(1.1 \%)$, textile production $(0.3 \%)$, etc. suffered the most. The change in 
structure could not but affect the growth potential of the industrial sector.

It is expedient to assess the effectiveness of the state policy of sectoral and horizontal support of the industrial sector in the context of a specific institutional environment. As D. North pointed out, institutions provide the incentive structure of human interaction [13]. Together, such motives constitute a set of motivational levers that ensure the effective transfer of impulses from the state and the institutional environment to the market agents and encourage them to develop and, in this case, to achieve the goals of industrial modernization. To take them into account, indicators were selected that satisfy two conditions: 1) the availability of data for the researched period; 2) quantitative reflection of the most significant features of the institutional environment of modernization of the industrial sector.

In the view of the aforementioned, the Index of Economic Freedom (assessed by the Heritage Foundation) was chosen measured on the basis of 12 quantitative and qualitative factors grouped into four categories ("pillars" of economic freedom): 1) rule of law, property rights, state integrity, judicial effectiveness); 2) the amount of government intervention (government spending, tax burden, fiscal health); 3) regulatory effectiveness (freedom of enterprise, freedom of labor, monetary freedom); 4) open market (freedom of trade, freedom of investment and financial freedom) [14]. Each of the components is given the same weight in the scoring, so the deterioration of one of the indicators causes symmetrical changes in the indicator itself. The range of components of the institutional environment covered by this indicator is wide, which allows to reduce the number of input variables.

Another indicator, which is not fully reflected in the Index of Economic Freedom, but, nevertheless, has a significant impact on the activities of the industrial sector, is the Regulatory Quality measured by the World Bank [15].

Considering the characteristics of basic institutions in this model does not seem possible because they are lowdynamic and difficult to quantify.

An important step of the modeling process is to take into account the fundamental change in state policy on industrial development after the signing of the Association Agreement between Ukraine and the EU. The Agreement, first of all, requires compliance with new principles in implementing state economic policy, namely shifting emphasis from sectoral to horizontal support, affecting the structure and volume of state funding for industrial development. For this purpose, we use two dummy variables: first take into consideration the industrial policy for 2005-2014 years (equals 1 these years, and 0 in others); second represents the industrial policy for 2015-2018 years (equals 1 these years, and 0 in others). The modeling also assumes that the influence of factors is manifested in the same time period in which there is a certain rate of growth of GVA in the industrial sector.

The initial array of data for model development for Ukraine is presented in в Table 1 .
Table 1. Initial data for modelling

\begin{tabular}{|c|c|c|c|c|c|c|}
\hline & $\mathbf{g}_{\mathbf{i}}^{*}$ & $\mathbf{P S}_{\mathbf{i}}$ & $\mathbf{C I}_{\mathbf{i}}$ & $\mathbf{S C}_{\mathbf{i}}$ & $\mathbf{E F}_{\mathbf{i}}$ & $\mathbf{Q L}_{\mathbf{i}}$ \\
\hline 2002 & 11.8 & 5.54 & 6 & 0.13 & 48.2 & 30.1 \\
\hline 2003 & 11.6 & 6.37 & 24.6 & 0.15 & 51.1 & 30.1 \\
\hline 2004 & 13.5 & 5.98 & 24.9 & 0.47 & 53.7 & 39.41 \\
\hline 2005 & 0.8 & 3.54 & 4.1 & 0.48 & 55.8 & 32.35 \\
\hline 2006 & 9.3 & 3.54 & 15.3 & 0.32 & 54.4 & 31.86 \\
\hline 2007 & 8.6 & 3.54 & 27 & 0.38 & 51.5 & 36.41 \\
\hline 2008 & $\square 3.3$ & 3.30 & $\square 5.3$ & 0.69 & 51 & 33.01 \\
\hline 2009 & $\square 19.1$ & 0.93 & $\square 32.4$ & 1.06 & 48.8 & 32.06 \\
\hline 2010 & 8.0 & 0.54 & $\square 9.5$ & 0.81 & 46.4 & 33.97 \\
\hline 2011 & 5.1 & 3.34 & 24.6 & 0.41 & 45.8 & 29.86 \\
\hline 2012 & $\square 1.5$ & 3.60 & 7.3 & 0.62 & 46.1 & 29.86 \\
\hline 2013 & $\square 7.7$ & 3.60 & 9.1 & 0.41 & 46.3 & 30.33 \\
\hline 2014 & $\square 10.9$ & 2.21 & $\square 25.7$ & 0.48 & 49.3 & 29.33 \\
\hline 2015 & $\square 14.8$ & 0.33 & $\square 19.9$ & 0.18 & 46.9 & 29.81 \\
\hline 2016 & 2.3 & 0.63 & 18.7 & 0.27 & 46.8 & 36.06 \\
\hline 2017 & 1.4 & 0.51 & 23.4 & 0.19 & 48.1 & 40.38 \\
\hline 2018 & 1.5 & 0.65 & 22.2 & 0.16 & 51.9 & 40.87 \\
\hline
\end{tabular}

$* g$ - real growth rate of industrial sector value added, $\% ; P S-$ share of governmental support of industry in the state budget total expenditures, \%; CI - real growth rate of capital investments in industrial sector, \%; $S C$ - structural changes in industrial sector, units; $E F$ - Index of Economic Freedom, points; $Q L$ - quality of legislation, point; $i$ - relevant year.

As the result we estimate the following multiple linear regression (5):

$$
\begin{aligned}
g_{i}=a+b_{1} P S_{i}+ & b_{2} C I_{i}+b_{3} S C_{i}+b_{4} E F_{i}+b_{5} Q L_{i}+ \\
& +A_{1} D_{1 i}+A_{2} D_{2 i}+\varepsilon_{i},
\end{aligned}
$$

where $D_{1}, D_{2}$ - dummy variables which splitting up the industrial policy into periods of 2005-2014 and 20152018 years; $a, A_{1}, A_{2}, b_{1} \ldots b_{6}$ - regression coefficients; $\varepsilon$ - error; $i$ - year.

Given that the factor values are different, the data were standardized, and the model was evaluated in the standardized form (6):

$$
\begin{aligned}
t\left(g_{i}\right)=\alpha & +\beta_{1} t\left(P S_{i}\right)+\beta_{2} t\left(C I_{i}\right)+\beta_{3} t\left(S C_{i}\right)+\beta_{4} t\left(E F_{i}\right)+ \\
& +\beta_{5} t\left(Q L_{i}\right)+K_{1} D_{1 i}+K_{2} D_{2 i}+u_{i},
\end{aligned}
$$

where $t(\cdot)$ are relevant standardized variable, $\alpha, \beta_{1 \ldots} \beta_{5}$, $K_{1}, K_{2}$ are coefficients of standardized regression.

Let us specify, that the dummy variables were not standardized that is why the model still has an intercept $\alpha$. Standardized data are presented in Table 2.

Table 2. Standardized data for modelling

\begin{tabular}{|c|c|c|c|c|c|c|}
\hline & $\mathbf{g}_{\mathbf{i}}$ & $\mathbf{P S}_{\mathbf{i}}$ & $\mathbf{C I}_{\mathbf{i}}$ & $\mathbf{S C}_{\mathbf{i}}$ & $\mathbf{E F}_{\mathbf{i}}$ & $\mathbf{Q L}_{\mathbf{i}}$ \\
\hline 2002 & 1.1 & 1.4 & -0.04 & -1.1 & -0.4 & -0.8 \\
\hline 2003 & 1.1 & 1.8 & 0.9 & -1.1 & 0.5 & -0.8 \\
\hline 2004 & 1.3 & 1.6 & 1.0 & 0.2 & 1.3 & 1.6 \\
\hline
\end{tabular}




\begin{tabular}{|c|c|c|c|c|c|c|}
\hline 2005 & 0.0 & 0.4 & -0.1 & 0.2 & 2.0 & -0.2 \\
\hline 2006 & 0.9 & 0.4 & 0.4 & -0.4 & 1.5 & -0.4 \\
\hline 2007 & 0.8 & 0.4 & 1.1 & -0.2 & 0.6 & 0.8 \\
\hline 2008 & -0.4 & 0.2 & -0.6 & 1.0 & 0.5 & -0.1 \\
\hline 2009 & -2.1 & -1.0 & -2.1 & 2.5 & -0.2 & -0.3 \\
\hline 2010 & 0.7 & -1.1 & -0.9 & 1.5 & -1.0 & 0.2 \\
\hline 2011 & 0.4 & 0.3 & 0.9 & 0.0 & -1.2 & -0.9 \\
\hline 2012 & -0.3 & 0.4 & 0.0 & 0.8 & -1.1 & -0.9 \\
\hline 2013 & -0.9 & 0.4 & 0.1 & 0.0 & -1.0 & -0.7 \\
\hline 2014 & -1.2 & -0.3 & -1.7 & 0.2 & -0.1 & -1.0 \\
\hline 2015 & -1.6 & -1.3 & -1.4 & -1.0 & -0.8 & -0.9 \\
\hline 2016 & 0.1 & -1.1 & 0.6 & -0.6 & -0.9 & 0.7 \\
\hline 2017 & 0.0 & -1.2 & 0.9 & -0.9 & -0.5 & 1.8 \\
\hline 2018 & 0.1 & -1.1 & 0.8 & -1.0 & 0.7 & 1.9 \\
\hline
\end{tabular}

\section{Main findings of the study}

\subsection{Interpretation of the model results}

Using method of least squares we suggest the following estimations of standardized multiple linear regression (7):

$$
\begin{aligned}
& t\left(g_{i}\right)=2.35-1.33 \cdot t\left(P S_{i}\right)+1.03 \cdot t\left(C I_{i}\right)-0.28 \cdot t\left(S C_{i}\right)+ \\
& +0.21 \cdot t\left(E F_{i}\right)-0.13 \cdot t\left(Q L_{i}\right)-2.17 \cdot D_{l i}-4.54 \cdot D_{2 i}, \quad(7)
\end{aligned}
$$

Statistical estimations of the coefficients and quality of the model are presented in Tables 3, 4, and 5 .

Table 3. Regression statistics

\begin{tabular}{|c|c|}
\hline Multiple $\mathrm{R}$ & 0.93095 \\
\hline $\mathrm{R}^{2}$ & 0.86667 \\
\hline Adjusted $\mathrm{R}^{2}$ & 0.76296 \\
\hline Standard Error & 0.48686 \\
\hline Observations & 17 \\
\hline
\end{tabular}

Table 4. Analysis of variance

\begin{tabular}{|c|c|c|c|c|c|}
\hline $\begin{array}{c}\text { Source of } \\
\text { Error }\end{array}$ & $\mathbf{d f}$ & $\begin{array}{c}\text { Sum of } \\
\text { Squares }\end{array}$ & MS & F & Significance F \\
\hline Regression & 7 & 13.87 & 1.98 & 8.36 & 0.0025 \\
\hline Residual & 9 & 2.13 & 0.24 & $\square$ & $\square$ \\
\hline Total & 16 & 16 & $\square$ & $\square$ & $\square$ \\
\hline
\end{tabular}

"-" no data

Table 5. Parameters estimation

\begin{tabular}{|c|c|c|c|c|}
\hline & Coefficients & $\begin{array}{c}\text { Standard } \\
\text { Error }\end{array}$ & t Stat & P-value \\
\hline Intercept & 2.346 & 0.708 & 3.3145 & 0.0090 \\
\hline$t\left(P S_{t}\right)$ & $\square 1.334$ & 0.529 & $\square 2.5240$ & 0.0326 \\
\hline$t(C I t)$ & 1.033 & 0.312 & 3.3110 & 0.0091 \\
\hline$t\left(S C_{t}\right)$ & $\square 0.280$ & 0.292 & $\square 0.9591$ & 0.3626 \\
\hline$t\left(E F_{t}\right)$ & 0.210 & 0.190 & 1.1050 & 0.2978 \\
\hline$t\left(Q L_{t}\right)$ & $\square 0.126$ & 0.307 & $\square 0.4119$ & 0.6900 \\
\hline$t\left(D_{1}\right)$ & $\square 2.173$ & 0.748 & $\square 2.9067$ & 0.0174 \\
\hline$t\left(D_{2}\right)$ & $\square 4.536$ & 1.287 & $\square 3.5245$ & 0.0065 \\
\hline
\end{tabular}

Statistical estimations of the coefficients and quality of the model give grounds to confirm the theoretical calculations of D. Rodrick on the negative impact of state support on the productivity of the industrial sector. Together with the real growth of capital investment and the type of policy, this factor turned out to be significant, and the model as a whole was adequate. The coefficients of the model (except for those near the dichotomous variables) show on how many standard deviations $\sigma_{g}$ will the rate of GVA growth of the industrial sector $g$ increase if the explanatory variable increases by one standard deviation $\sigma_{x}$. Budget expenditures for various purposes to ensure the development of the industrial sector with an increase of one sigma $(2 \%)$ cause a reduction in the growth rate of GVA in the industrial sector by 1.33 sigma (or 12.8\%). In turn, capital investment, increasing by one sigma (by $19.1 \%$ ), causes an increase in growth by 1.03 sigma (by $9.9 \%$ ).

In the model (7), the coefficients for the variable structural shifts and institutional factors were statistically insignificant.

Within the sample, structural shifts had negative effects on the growth of the industrial sector, which may indirectly indicate the destructive nature of such structural changes. The index of economic freedom, in turn, as a reflection of the institutional environment of the economy, has a positive effect on the growth of the industrial sector. And the low quality of the Ukrainian legal framework governing the economic activity of the industrial sector has forced Ukrainian businesses to adapt and develop their own mechanisms of life in the current environment, so a slight improvement in the legal framework, which reduced protectionism and decreased sectoral subsidies, together with the incompletion of deregulation and judicial reforms, had a negative impact.

Binary variables, which denote the implementation of elements of sectoral or horizontal industrial policy, demonstrate their negative impact on the growth of the sector. However, the negative impact of the 2005-2014 policy reduces the value of the standardized variable of the growth rate of GVA in the industrial sector by 2.17 units, which still leads to its positive values in general (7):

$$
\alpha-K_{l}=2.35-2.17=0.18 .
$$

In turn, the policy of 2015-2018, which is characterized by a sharp reduction in government support, with the elimination of the impact of other variables, causes a significant decline in the growth rate of gross value added:

$$
\alpha-K_{2}=2.35-4.54=-2.19 .
$$

This is somewhat at odds with the inverse relationship between the growth of government support and the gross 
value added of the industrial sector. The solution to this contradiction lies in the plane of structural changes in the course of modernization: the allocation of resources to support medium- and high-tech activities, rather than traditional, stagnant industries, can change the results of modeling. Hence the thesis of the need for state support, which, although not able to eliminate all the "failures", can stimulate the modernization of the industrial sector through reasonable intervention.

\subsection{Policy recommendations}

The obtained results show the necessity of revision the conceptual base for industrial policy in Ukraine especially in terms of introduction of new Ministry on Issues of Strategic Industries of Ukraine. Its major designation is promoting the development of high-tech sectors of manufacturing.

The provision of optimal proportion between horizontal and vertical measures of matrix industrial policy should be ensured considering:

- historical background to neutralize market shocks while changing the paradigm of economic policy;

- business readiness and level of competitiveness to keep it in reforms;

- economic expediency, in particular, in considering old low-value-added economic activities for support;

- institutional and budget capabilities, which influence the speed of reforms;

- determination of sunrise industries of medium- and high-tech levels and their specific needs;

- careful selection of policy instruments to maintain their congruency to goals of industrial development.

\section{Conclusions}

Thus, the empirical analysis of the model allowed us to confirm the theoretical assumptions about the impossibility of full compensation for the distortion of market mechanisms through government support, as well as the importance of capital investment and changes in industrial policy. It was also found that the structure of state support and its scope should be revised to improve the effectiveness of horizontal instruments. In the environment of weak institutions of Ukraine, the instruments of horizontal policy most likely are less effective than sectoral policy measures. The implementation of selective instruments is limited in terms of international agreements on Association with EU or WTO. Thus, Ukraine should construct the configuration of its mixed vertical-horizontal model of industrial policy in order to achieve the maximum economic effect (increasing the growth rate of gross value added to state resources, increasing the share of exports of medium and high-tech products, and wages in the industrial sector).

\section{References}

1. D. Rodrik, Normalizing Industrial Policy (The International Bank for Reconstruction and Development, The World Bank, Washington, 2008)

2. R. Beason, D. E. Weinstein, The Rev. of Econ. and Stat. 78 (2), 286 (1996)

3. C. Criscuolo, R. Martin, H.G. Overman, J. Van Reenen, Americ. Econ. Rev. 109 (1), 48 (2019)

4. A.O. Krueger, B. Tuncer, Americ. Econ. Rev. 72 (5), 1142 (1982)

5. R.Z. Lawrence, D.E. Weinstein, NBER WP 7264 (1999)

6. J.-W. Lee, J. Econ. Gr. 1, 391 (1996)

7. R. Stöllinger, N. Foster-McGregor, M. Holzner, M. Landesmann, J. Pöschl, R. Stehrer. Res. Reports, 391 (2013)

8. J. Wang, Res. Pol. 47 (2), 399 (2017). doi:10.1016/j.respol.2017.12.008

9. H.-Y. Joo, H. Suh, Sustainability 9, 1980 (2017). doi:10.3390/su9111980

10. J. Chen, L. Xie, Front. Bus. Res. Of China 13, 18 (2019). doi:10.1186/s11782-019-0065-y

11. Y. Higuchi, G. Shimada, Industrial Policy, Industrial Development, and Structural Transformation in Asia and Africa, in Paths to the Emerging State in Asia and Africa. Eds. K. Otsuka, K. Sugihara, 195 (2019). doi:10.1007/978-981-133131-2_9

12. B. Buhm, L.F. Punzo, Productivity - investment fluctuations and structural change, in Growth and Structural Change. Eds. L.S. Punzo, L. Cycles, 47 (2006)

13. D. C. North, Institutions, Institutional Change and Economic Performance (Cambridge University Press, 1990)

14. Heritage Foundation, Index of Economic Freedom, https://www.heritage.org/index/ranking

15. Worldwide Governance Indicators: Country Data Report, The World Bank.

http://info.worldbank.org/governance/wgi/index.asp $\mathrm{x} \#$ countryReports 